\title{
Determining the Optical Quality of Focusing Collectors Without Laser Ray Tracing
}

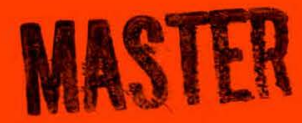

Paul Bendt

Harry W Gaul

Ari Rabl
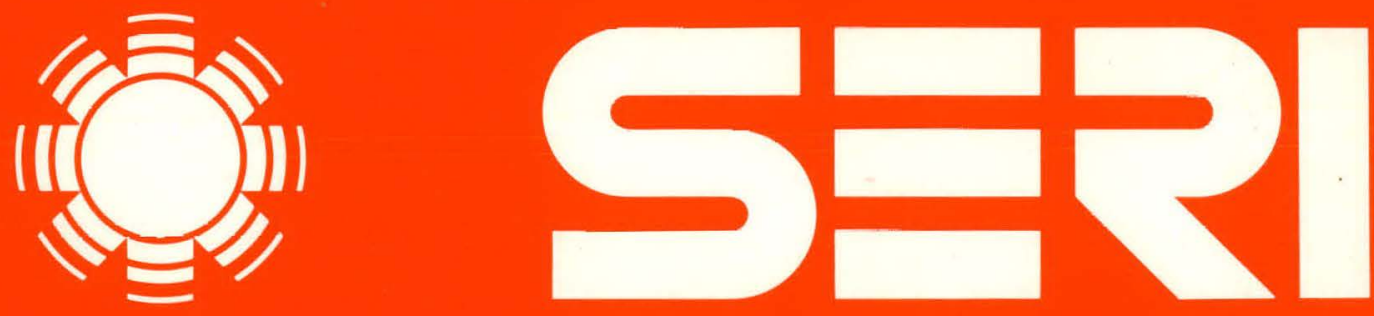

Solar Energy Research Institute

A Division of Midwest Research Institute

1617 Cole Boulevard

Golden, Colorado 80401

Operated for the

U.S. Department of Energy

under Contract No. EG-77-C-01-4042 


\section{DISCLAIMER}

This report was prepared as an account of work sponsored by an agency of the United States Government. Neither the United States Government nor any agency Thereof, nor any of their employees, makes any warranty, express or implied, or assumes any legal liability or responsibility for the accuracy, completeness, or usefulness of any information, apparatus, product, or process disclosed, or represents that its use would not infringe privately owned rights. Reference herein to any specific commercial product, process, or service by trade name, trademark, manufacturer, or otherwise does not necessarily constitute or imply its endorsement, recommendation, or favoring by the United States Government or any agency thereof. The views and opinions of authors expressed herein do not necessarily state or reflect those of the United States Government or any agency thereof. 


\section{DISCLAIMER}

Portions of this document may be illegible in electronic image products. Images are produced from the best available original document. 
Printed in the United States of America Available from:

National Technical Information Service

U.S. Department of Commerce

5285 Port Royal Road

Springfield, VA 22161

Price:

50

Microfiche $\$ 3.00$

Printed Copy $\$ 4.50$

\begin{abstract}
NOTICE
This report was prepared as an account of work sponsored by the United States Government. Neither the United States nor the United States Department of Energy, nor any of their employees, nor any of their contractors, subcontractors, or their employees, makes any warranty, express or implied, or assumes any legal liability or responsibility for the accuracy, completeness or usefulness of any information, apparatus, product or process disclosed, or represents that its use would not infringe privately owned rights.
\end{abstract}


SERI /TR-333-359

UC. CATEGORY: UC-62

DETERMINING THE OPTICAL

QUALITY OF FOCUSING COLLECTORS

WITHOUT LASER RAY TRACING

P. BENDT

H. W. GAUL

A. RABL

FEBRUARY 1980

PREPARED UNDER TASK No. 3432.10

\section{Solar Energy Research Institute}

1536 Cole Boulevard

Golden, Colurado 80401

A Division of Midwest Research Institute

Prepared for the

U.S. Department of Energy

Contract No. EG $\cdot 77 \cdot C \cdot 01 \cdot 4042$ 


\section{THIS PAGE}

\section{WAS INTENTIONALLY \\ LEFT BLANK}




\section{FÖREWORD}

A preliminary version of this report (How to Measure the Optical Quality of Focussing Solar Collectors Without Laser Ray Tracing; SERI/TP-34-251) was presented at the 1979 Silver Jubilee International Congress of the International Solar Energy Soclety in Joint Meeting with the American Section of the International Solar Energy Society, Inc., May 28 through June 1, 1979 in At lanta, Georgia.

The authors thank F. Biggs and his colleagues at Sandia Laboratories for a careful review of this report.

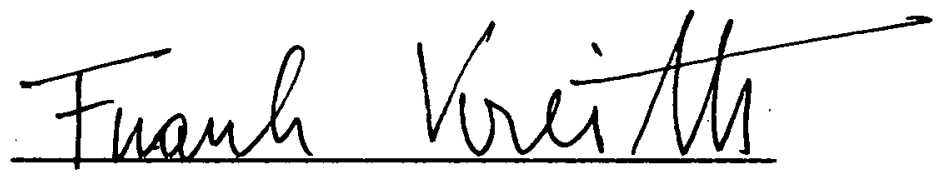

Frank Kreith

Branch Chief

Thermal Conversion Branch

Approved for:

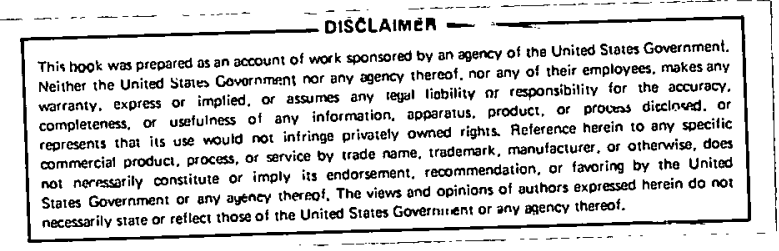

SOLAR ENERGY RESEARCH INSTITUTE

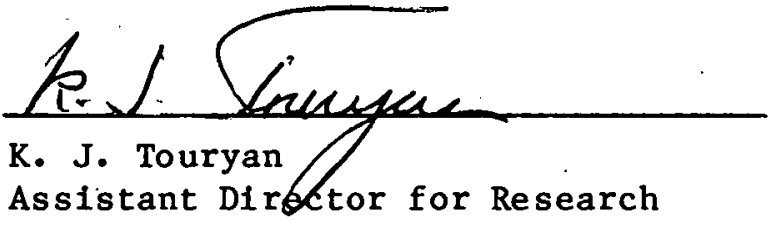


THIS PAGE

\section{WAS INTENTIONALLY \\ LEFT BLANK}




\section{ABSTRACT}

This paper describes a novel alternative to the laser ray trace technique for evaluating the optical quality of focusing solar collectors. The new method does not require any-equipment beyond that which is used for measuring collector efficiency; it could therefore become part of routine collector testing. The total optical errors resulting from imperfect specularity and from inaccuracies in reflector position or slope are characterized by an an-

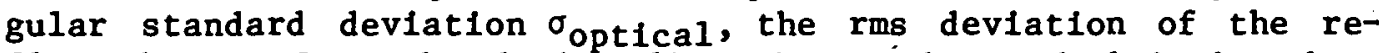
flected rays from the design direction. The method is based on the fact that the off-axis performance of a concentrator depends on $\sigma_{\text {optical }}$. An angular scan is performed; 1.e., the collector output is measured as a function of misalignment angle over the entire range of angles for which there is measurable output (typically a few degrees). This test should be carried out on a very clear day, with the recelver close to ambient temperature (if the latter condition cannot be satisfled, appropriate corrections are necessary). The parameter $\sigma_{\text {optical }}$ is then determined by a leastsquares fit between the measured and the calculated angular scan. We tested the method on a parabollc trough collector manufactured by Hexcel, but it is suitable for parabolic dishes as we11. 


\section{THIS PAGE}

WAS INTENTIONALLY

LEFT BLANK 
TABLE OF CONTENTS

Nomenclature......................................... ix

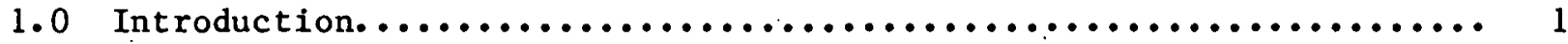

2.0 Theory.......................................... 3

3.0 Experiment....................................... 11

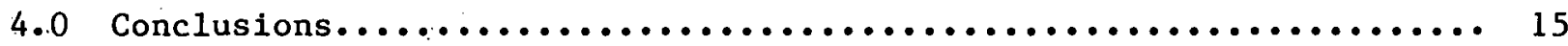

References........................................... 17 
2-1 Coefficients of Angular Acceptance Function for a Parabolic

Dish with Flat Receiver................................

LIS'T OF FIGURES

2-1 Intercept Factor vs. Misalignment Angle for $\sigma_{\text {optical }}=0,5$,

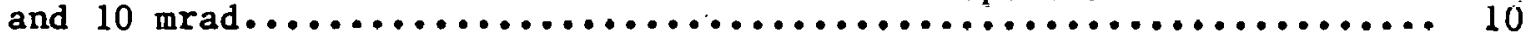

3-1 Test Data of Optical Efficiency vs. Misalignment Angle........... 10 
NOMENCLATURE

$B_{\text {eff }}(\theta)$

B $_{\text {sun, }} \operatorname{radial}(\theta)$

$B_{\text {sun, } 1 \text { inear }}\left(\theta_{\perp}\right)$

C

$f(\theta)$

$\mathrm{I}_{\mathrm{b}}$

$\alpha$

$\gamma\left(\theta_{m}\right)$

$\eta$

no

$\theta_{1}$

$\theta_{\|}$

$\theta_{\mathbf{m}}$

$\rho$

$(\rho \tau \alpha)$

$\sigma_{\text {contour }}$

$\sigma_{\text {displacement }}$

$\sigma_{\text {specular }}$

optical

$\sigma_{\text {sun }}$

$\sigma_{\text {tracking }}$

$\sigma$

$\tau$

$\phi$
Effective source obtained as convolution of $B_{\text {sun }}$ with error distribution

Angular brightness distribution of the sun for point focus geometry (W/m $\mathrm{m}^{2}$ sterad)

Angular brightness distribution of the sun for line focus geometry $\left(W / m^{2} \mathrm{rad}\right)$.

Geometric concentration ratio (for example, a trough of aperture width $D$ and receiver tube diameter $d$ has $C=D / \pi d$ )

Angular acceptance function

Beam Irradiance as measured by pyrhellometer $\left(\mathrm{W} / \mathrm{m}^{2}\right)$, also called direct insolation

Absorptance of receiver

Intercept factor if. collector is misaligned, that is, with its optical axis pointing an angle $\theta_{\mathrm{m}}$ away from the sun

$q_{\text {net }} / I_{b}=$ collector efficiency

Optical efficiency $=(\rho \tau \alpha) \gamma$

Projection of incidence angle on plane perpendicular to tracking axis

Projection of incidence angle on plane of tracking axis and optical axis

Misalignment angle $=$ angle from center of sun to axis or plane of symmetry of collector

Reflectance of reflector

Effective reflectance-transmittance-absorptance product of collector

rms angular deviation of contour from design direction

Equivalent rms angular spread that accounts for imperfect placement of receiver relative to reflector

rms spread of reflected beam due to imperfect specularity , of reflector material

rms angular spread caused by all optical errors

rms angular width of sun in line focus geometry

rms angular" tracking error

Total rms beam spread

Transmittance of collector glazing, if any

Rim angle 
SECTION 1.0

INTRODUCTION

Evaluation of the optical quality of a solar concentrator is important: to the designer, to tell him whether a collector needs improvement; and to the manufacturer, to ensure proper quality control. In addition to the optical efficiency $\eta_{0}$, it is important to have a measure of optical errors and of losses due to reflected radiation missing the receiver. The methods that are available or have been proposed for measuring the contour accuracy of solar concentrators require either laser ray tracing or flux mapping at the receiver surface. Both approaches can provide accurate results, but the equipment is specialized and expensive and demands a good deal of time and/or expertise $[1,2]$.

The question arises, therefore, whether the instantaneous efficiency measurements that are performed as part of a standardized performance evaluation [3]

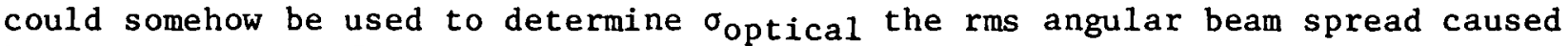
by optical imperfections. This paper shows that this can indeed be accomplished by misaligning the collector slightly away from the sun and measuring the efficiency for several values of the misalignment angle. The optical error $\sigma_{\text {optical }}$ is then extracted by finding the theoretical curve that best fits these misalignment data. Thus, the determination of $\sigma_{\text {optical, could be- }}$ come part of the standard test procedures for concentrating solar collectors. In a sense, this method employs the receiver itself as flux mapper. Compared to conventional flux mapping with point-like detectors, the present method is much simpler experimentally. The method is suitable for both photovoltaic and thermal collectors.*

The theory underlying this technique is described in Section 2.0. Section 3.0 presents the test results for a parabolic trough collector with cylindrical receiver, manufactured by Hexcel. The data obtained with this collector indicate that the reproducibility of this method is good (on the order of $\pm 5 \%$ ).

Unfortunately, a laser ray trace appaiatus was not available for an independent determination of $\sigma_{\text {optical. }}$

*In some photovoltaics concentrators, the reflector is designed for uniformity of flux distribution and is not a parabola. The method is still applicable, but the angular acceptance function $f(\theta)$ in $F_{r} \cdot 2-9$ would have to be recalculated for the data analysis. 


\section{SE기누}




\section{SECTION 2.0}

\section{THEORY}

Since the theory of focusing solar collectors has been described elsewhere [4,5], a brief summary suffices at this point. The cructal concepts are the angular acceptance function and the'intercept factor. The angular acceptance function $f(\theta)$ is defined as that fraction of a uniform beam of parallel rays incident on the aperture at an angle $\theta$ from the symmetry axis that reaches the recelver if the optics are perfect; $f(\theta)$ accounts for off-axis aberrations. Eqs. 2-1 and 2-2 list the angular acceptance function for parabolic trough and dish reflectors with round and with flat receivers. The rim angle is $\phi$ and the geometric concentration ratio $\mathrm{C}$, defined as the ratio of the aperture area to the absorber surface area.

For a parabolic trough with cylindical recefver, the angular acceptance function is

$$
\mathrm{f}_{\text {trough, }} \operatorname{cyl}(\theta)=\left\{\begin{array}{l}
1 \text { for }|\theta|<\theta_{1} \\
\cot \frac{\phi}{2}\left(\frac{2 \tan (\phi / 2)}{\pi C \theta}-1\right)^{1 / 2} \\
\text { for } \theta_{1}<|\theta|<\theta_{2} \\
0 \text { for }|\theta|>\theta_{2} .
\end{array}\right.
$$

where

$$
\begin{aligned}
& \theta_{1}=\frac{\sin \phi}{\pi C} \\
& \theta_{2}=\frac{2 \tan (\phi / 2)}{\pi C^{2}} .
\end{aligned}
$$

For a parabolic dish with spherical receiver, the angular acceptance function is the square of Eq. 2-1a, with the replacement of $\pi \mathrm{C}$ by $2 \sqrt{ } \mathrm{C}$ :

$$
\mathrm{f}_{\mathrm{dish}} \text { sphere }(\theta)=\left\{\begin{array}{c}
1 \text { for } \theta<\theta_{1} \\
\cot ^{2} \frac{\phi}{2}\left(\frac{2 \tan (\phi / 2)}{2 \theta \sqrt{C}-1}\right) \\
\text { for } \theta_{1}<\theta<\theta_{2} \\
0 \text { for } \theta_{2}<\theta,
\end{array} .\right.
$$


with

$$
\theta_{1}=\frac{\sin \phi}{2 \sqrt{ } C}
$$

and

$$
\theta_{2}=\frac{2 \tan (\phi / 2)}{2 \sqrt{ } \mathrm{C}}
$$

For a parabolic trough with flat one-sided receiver, $f(\theta)$ is given by

$$
f_{\text {trough, flat }}(\theta)=\left\{\begin{array}{l}
1 \text { for }|\theta|<\theta_{1}, \\
\cot \frac{\phi}{2}\left\{\left[\left(4+\frac{\tan \frac{\phi}{2}}{\theta c}\right) \frac{\operatorname{tall} \frac{\phi}{2}}{\theta c}\right]^{1 / 2}-1-\frac{\tan \frac{\phi}{2}}{\theta c}\right)^{1 / 2} \\
\text { for } \theta_{1}<\theta<\theta_{2} \\
0 \text { for } \theta_{2}<|\theta|,
\end{array}\right.
$$

with

$$
\theta_{1}=\frac{\sin \phi \cos \phi}{C}
$$

and

$$
\theta_{2}=\frac{2}{C} \tan \frac{\phi}{2}
$$

For a parabolic dish with flat one-sided receiver, the exact expression for the angular acceptance function is more complicated. For practical applications, however, the following polynomial fit is acceptable:

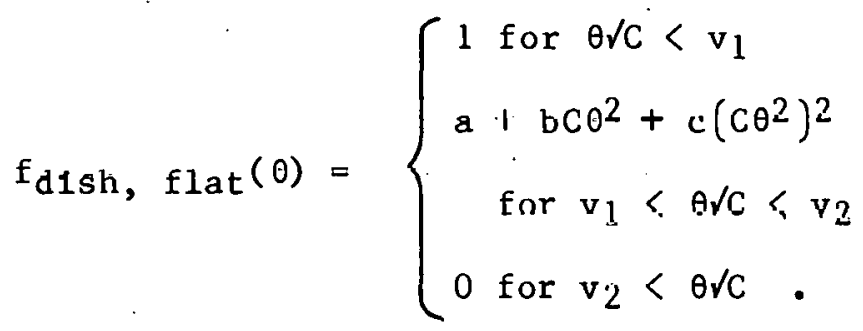

The coefficients $a, b, c, v_{1}$, and $v_{2}$ depend on rim angle and are tabulated in Table 2-la; a more accurate four-term expansion with an additional term $\mathrm{d}\left(\mathrm{C} \theta^{2}\right)^{3}$ is given in Table 2-1b. Implicit in Eq. 2-1 and 2-2, and throughout this paper, is the assumption that the concentration is high enough ( $C \geqslant 10$ for line-focus and $C \geqslant 100$ for point-focus concentrator) to permit the approximation of $\sin \theta$ by $\theta$. 
Table 2-1. COEFFICIENTS OF ANGULAR ACCEPTANCE FUNCTION FOR A PARABOLIC DISH WITH FLAT RECEIVER: THREE-PARAMETER FIT (a), FOUR-PARAMETER FIT (b)

\begin{tabular}{|c|c|c|c|c|c|c|c|}
\hline (a) & $\begin{array}{c}\phi \\
\text { [degrees] }\end{array}$ & $a$ & b & c & $\mathrm{v}_{1}$ & $\mathrm{v}_{2}$ & \\
\hline & $\begin{array}{l}30 \\
35 \\
40 \\
45 \\
50 \\
55 \\
60\end{array}$ & $\begin{array}{r}-1.8660 \\
0.2309 \\
0.8866 \\
1.1738 \\
1.2646 \\
1.2466 \\
1.2075\end{array}$ & $\begin{array}{r}32.1042 \\
8.7987 \\
2.4950 \\
0.0861 \\
-0.7577 \\
-0.9444 \\
-0.9682\end{array}$ & $\begin{array}{r}-89.5992 \\
-23.7599 \\
-8.0311 \\
-2.7177 \\
-0.8522 \\
-0.2199 \\
0.0309\end{array}$ & $\begin{array}{l}0.4355 \\
0.4785 \\
0.5053 \\
0.5189 \\
0.5179 \\
0.4969 \\
0.4645\end{array}$ & $\begin{array}{l}0.5342 \\
0.6284 \\
0.7226 \\
0.8205 \\
0.9231 \\
1.0290 \\
1.1407\end{array}$ & . \\
\hline (b) & $\begin{array}{c}\phi \\
\text { [degrees] }\end{array}$ & $a$ & b & c & $\mathrm{d}$ & $\mathbf{v}_{1}$ & $\mathrm{v}_{2}$ \\
\hline & $\begin{array}{l}30 \\
31 \\
32 \\
33 \\
34 \\
35\end{array}$ & $\begin{array}{l}-4.4647 \\
-4.5916 \\
-3.2651 \\
-2.9694 \\
-2.6752 \\
-1.8817\end{array}$ & $\begin{array}{l}65.5256 \\
65.3298 \\
48.6801 \\
43.7084 \\
39.2132 \\
30.1432\end{array}$ & $\begin{array}{r}-231.6741 \\
-230.3732 \\
-165.7419 \\
-144.6810 \\
-126.3405 \\
-94.2664\end{array}$ & $\begin{array}{r}199.6752 \\
215.6702 \\
145.2926 \\
125.8221 \\
108.4094 \\
76.2152\end{array}$ & $\begin{array}{l}0.4365 \\
0.4806 \\
0.4536 \\
0.4517 \\
0.4598 \\
0.4682\end{array}$ & $\begin{array}{l}0.5346 \\
0.5536 \\
0.5726 \\
0.5916 \\
0.6107 \\
0.6298\end{array}$ \\
\hline & $\begin{array}{l}36 \\
37 \\
38 \\
39 \\
40\end{array}$ & $\begin{array}{l}-0.9984 \\
-0.8803 \\
-0.5546 \\
-0.2971 \\
-0.1744\end{array}$ & $\begin{array}{l}20.3357 \\
18.5920 \\
15.3131 \\
12.7096 \\
11.2891\end{array}$ & $\begin{array}{l}-60.3045 \\
-54.0918 \\
-44.0733 \\
-36.1594 \\
-31.6287\end{array}$ & $\begin{array}{l}41.6597 \\
37.6157 \\
29.8485 \\
23.7696 \\
20.5410\end{array}$ & $\begin{array}{l}0.4708 \\
0.4498 \\
0.4757 \\
0.4879 \\
0.4758\end{array}$ & $\begin{array}{l}0.6473 \\
0.6667 \\
0.6862 \\
0.7057 \\
0.7255\end{array}$ \\
\hline & $\begin{array}{l}41 \\
42 \\
43 \\
44 \\
45\end{array}$ & $\begin{array}{l}0.0281 \\
0.2034 \\
0.3484 \\
0.4679 \\
0.5406\end{array}$ & $\begin{array}{l}9.3233 \\
7.7235 \\
6.4039 \\
5.3146 \\
4.5794\end{array}$ & $\begin{array}{l}-25.9283 \\
-21.4737 \\
-17.8527 \\
-14.9032 \\
-12.8446\end{array}$ & $\begin{array}{r}16.2998 \\
13.1345 \\
10.6252 \\
8.6317 \\
7.2859\end{array}$ & $\begin{array}{l}0.4729 \\
0.4948 \\
0.4993 \\
0.4999 \\
0.4916\end{array}$ & $\begin{array}{l}0.7454 \\
0.7653 \\
0.7853 \\
0.8055 \\
0.8260\end{array}$ \\
\hline & $\begin{array}{l}46 \\
47 \\
48 \\
49 \\
50\end{array}$ & $\begin{array}{l}0.6616 \\
0.7394 \\
0.7824 \\
0.8420 \\
0.8969\end{array}$ & $\begin{array}{l}3.6087 \\
2.9432 \\
2.5347 \\
2.0125 \\
1.5651\end{array}$ & $\begin{array}{r}-10.449 .5 \\
-8.7703 \\
-7.7098 \\
-6.4216 \\
-5.3625\end{array}$ & $\begin{array}{l}5.7546 \\
4.7180 \\
4.1138 \\
3.3377 \\
2.7276\end{array}$ & $\begin{array}{l}0.5010 \\
0.5013 \\
0.4972 \\
0.4924 \\
0.4924\end{array}$ & $\begin{array}{l}0.8463 \\
0.8670 \\
0.8892 \\
0.9101 \\
0.9313\end{array}$ \\
\hline & $\begin{array}{l}51 \\
52 \\
53 \\
54 \\
55\end{array}$ & $\begin{array}{l}0.9437 \\
0.9788 \\
1.0122 \\
1.0388 \\
1.0557\end{array}$ & $\begin{array}{l}1.1781 \\
0.8666 \\
0.5920 \\
0.3587 \\
0.1827\end{array}$ & $\begin{array}{l}-4.4598 \\
-3.7263 \\
-3.1055 \\
-2.5779 \\
-2.1673\end{array}$ & $\begin{array}{l}2.2215 \\
1.8195 \\
1.4926 \\
1.2208 \\
1.0151\end{array}$ & $\begin{array}{l}0.4904 \\
0.4852 \\
0.4834 \\
0.4793 \\
0.4721\end{array}$ & $\begin{array}{l}0.9527 \\
0.9743 \\
0.9962 \\
1.0183 \\
1.0411\end{array}$ \\
\hline & $\begin{array}{l}56 \\
57 \\
58 \\
59 \\
60\end{array}$ & $\begin{array}{l}1.0762 \\
1.0897 \\
1.1025 \\
1.1123 \\
1.1166\end{array}$ & $\begin{array}{r}0.0037 \\
-0.1388 \\
-0.2654 \\
-0.3772 \\
-0.4623\end{array}$ & $\begin{array}{l}-1.7782 \\
-1.4587 \\
-1.1845 \\
-0.9430 \\
-0.7488\end{array}$ & $\begin{array}{r}0.8258 \\
0.6730 \\
0.5464 \\
0.4376 \\
0.3516\end{array}$ & $\begin{array}{l}0.4686 \\
0.4622 \\
0.4575 \\
0.4514 \\
0.4425\end{array}$ & $\begin{array}{l}1.0637 \\
1.0865 \\
1.1096 \\
1.1329 \\
1.1565\end{array}$ \\
\hline
\end{tabular}


The intercept factor $\gamma\left(\theta_{m}\right)$ is that fraction of rays from the sun that reaches the recelver of a collector with real optical errors when the optical axis is misaligned by an angle $\theta_{\mathrm{m}}$ from the center of the sun. The intercept factor is the convolution of the normalized angular brightness distribution of the sun, the distribution of optical errors, and the angular acceptance function for perfect optics.

The brightness distribution of the sun has been measured by the Lawrence Berkeley Laboratory circumsolar telescope as brightness $B_{\text {sun, }}$ radial $(\theta)$ in $\mathrm{W} / \mathrm{m}^{2}$ steradians at an angle $\theta$ from the center of the solar disk. To yield the dimensionless intercept factor, $B_{\text {sun }}$ must be normalized by the beam irradiance:

$$
I_{b}=2 \pi \int_{0}^{2.8^{\circ}} d \theta \quad \theta B_{\text {sun, }} \operatorname{radial}(\theta)
$$

(The upper integration limit corresponds to the acceptance half-angle of the pyrhellometer, the instrument which is customarily used for measuring the socalled direct or beam insolation.) For line focus collectors, it is convenient to transform to the linear brightness distribution (in $\mathrm{W} / \mathrm{m}^{2}$ ):

$B_{\text {sun, linear }}\left(\theta_{\perp}\right)=2 \int_{0}^{2.8^{\circ}} \mathrm{d} \theta_{\|} B_{\text {sun, }}$ radial $\left[\left(\theta_{\|}{ }^{2}+\theta_{\perp}^{2}\right)^{1 / 2}\right]$,

where $\theta_{1}$ is the angular coordinate in the plane normal to the focal line and $\theta_{\|}$the angular coordinate parallel to the focal line.

To standardize the tests described in this paper, it is advisable to take data only when the sky is very clear. The rms width of the sun under such conditinns is

$$
\sigma_{\text {sun, }} 11 \text { near }=2.6 \pm 0.1 \mathrm{mrad}
$$

for line focus collectors, and

$$
1 \quad \sigma_{\text {sun, }} \text { radial }=3.5 \pm 0.1 \mathrm{mrad}
$$

for point focus collectors. The variation of the brightness distribution between clear days (ratio of circumsolar over beam irradiancé less than one percent) is sufficiently small that the analysis of the misalignment data can be based on the standard ecan in Table 4-1 uf Ref. [6] it a circumsolar telescope is not available.

In a solar concentrator, several statistically independent factors contribute to the optical error: contour errors, lack of perfect specularity [7], tracking errors (wliell averaged over time), and deformation and displacement of the receiver. 
Each error type can be characterized by its rms angular width (one-sided deviation from the design. direction). The dispersion optical for the total optical error is obtained by adding the squares of the individual dispersions:

$$
\begin{aligned}
\sigma_{\text {optical }}^{2}= & 4 \sigma_{\text {contour }}^{2}+\sigma_{\text {specular }}^{2} \\
& +\sigma_{\text {displacement }}^{2}+\sigma_{\text {tracking }}^{2} .
\end{aligned}
$$

( $\sigma_{\text {contour }}$ is multiplied by two because of Snell's law; in Fresnel reflectors, $\sigma_{\text {tracking }}$ must also be multiplied by two.)

Note that this rule for combining standard deviations is valid regardiess of the shape of the individual error distributions; they could be Gaussian, boxlike, or anything else, since all distributions under discussion have zero mean. The total beam width $\sigma$ is obtained by adding the rms width of the sun according to

$$
\sigma^{2}=\sigma_{\text {optical }}^{2}+\sigma_{\text {sun }}^{2}
$$

Measurements of reflector surfaces [1] have shown that the distributions cor-

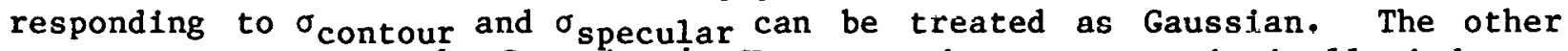
terms may or may not be Gaussian. $\star$ However, when many statistically independent distributions are convoluted, the result is nearly Gaussian unless a single non-Gaussian contribution dominates [8]. In the case of focusing solar collectors, the Gaussian contour errors appear to be the largest, and a Gaussian approximation for the total optical error is reasonable; this is assumed for the rest of the paper.

The order of carrying out the convolution of angular acceptance function, solar brightness, and optical errors is immaterial. Let us first convolute the solar brightness distribution with a Gaussian distribution of optical errors to obtain the so-called effective source. For line focus geometry, the effective source depends only on $\theta_{\perp}$.

$$
\begin{aligned}
& \mathrm{B}_{\text {eff, Iinear }}\left(\theta_{\perp}\right)=\int_{-\infty}^{\infty} \mathrm{d} \theta_{\perp}^{\prime} \mathrm{B}_{\text {sun, }} \text { linear }\left(\theta_{\perp}-\theta_{1}^{\prime}\right) \\
& \times \exp \left(-\frac{\theta_{1}^{\prime 2}}{2 \sigma_{\text {optical }}^{2}}\right) /\left(\sqrt{2 \pi} \cdot \sigma_{\text {optical }}\right) .
\end{aligned}
$$

*Receiver displacements may be parallel or perpendicular to the aperture (or some combination), and the corresponding error distribution will in general not be Gaussian for a single collector module. Averaged over a large array of collectors, a Gaussian approximation for the displacement error distribution is likely, however, to be quite good. 
The point focus case requires two-dimensional convolutions, and it is convenient to write the angles as two-dimensional vectors $\theta$. Because of azimuthal symmetry, the effective source for point focus collectors depends only on $\theta=|\vec{\theta}|$.

$$
\begin{aligned}
B_{e f f}, \operatorname{radial}(\theta)= & \iint_{-\infty}^{\infty} \mathrm{d} \theta_{x}^{\prime} \mathrm{d} \theta_{y}^{\prime} B_{\text {sun }}, \operatorname{radial}\left(\left|\vec{\theta}-\vec{\theta}^{\prime}\right|\right) \\
& \times \exp \left(-\frac{\left|\theta^{\prime}\right|^{2}}{2 \sigma_{\text {optical }}^{2}}\right) /\left(2 \pi \sigma_{\text {optical }}^{2}\right) .
\end{aligned}
$$

Finally, the intercept factor as a function of misalignment angle $\theta_{\mathrm{m}}$ is obtained as a convolution of effective source and angular acceptance functions. For line focus collectors, $\theta_{\mathrm{m}}$ is weasured in the plane normal to the focal line, and the intercept factor is

$\gamma_{\text {Iinear }}\left(\theta_{m}\right)=\int_{-\infty}^{\infty} d \theta_{\perp} f_{\text {linear }}\left(\theta_{m}-\theta_{\perp}\right) B_{\text {eff }}, 1$ 1near $\left(\theta_{\perp}\right) / I_{b}$.

(If the incidence angle along the trough is nonzero, for example in a collector with an east-west tracking axis at times other than solar noon, $\theta_{m}$ is the projection of the incidence angle on the plane normal to the tracking axis.) For point focus collectors with azimuthal symmetry, the intercept factor depends only on $\theta_{m}=\left|\vec{\theta}_{m}\right|$, the angle between the center of the sun and the symmetry axis of the collector:

$\gamma_{\operatorname{radial}}\left(\theta_{\mathrm{m}}\right)=\iint_{-\infty}^{\infty} \mathrm{d} \theta_{\mathrm{x}}^{\prime} \mathrm{d} \theta_{\mathrm{y}}^{\prime} \mathrm{f}_{\mathrm{radial}}\left(\left|\vec{\theta}_{\mathrm{m}}-\vec{\theta}^{\prime}\right|\right) \mathrm{B}_{\text {eff }}, \operatorname{radial}\left(\left|\vec{\theta}^{\prime}\right|\right) / \mathrm{I}_{\mathrm{b}} \cdot(2-9 \mathrm{~b})$

In a real. point focus collector, axial symmetry may be viulaced by gravity induced deformations and by manufacturing defects. To test for such a possibility, the angular scan should be performed in different azimuthal directions.

For parabolic reflectors, $f_{1 \text { inear }}$ and $f_{\text {radial }}$ are given in Eqs. 2-1 and 2-2; for other linear concentrator-types, they can be calculated by the method described in Refs. 4 and 5.

A convenient approximation is permitted if the optical errors are sufficiently

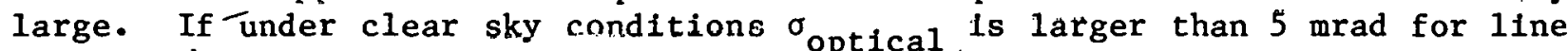
focus and 10 mrad for point focus collectors, the intercept factor ls quite insensirlve to detalls of the sun shape and the effective source can be replaced by a Gaussian distribution $[2,4]$. Since this is the case for the current generation of parabolic trough collectors [1], we have made this approximation for the data analysis in this paper; in other words, we have calculated the intercept factor according to

$\gamma_{\text {trough, Gauss }}\left(\theta_{m}\right)=\int_{-\infty}^{\infty} d \theta_{\perp} f_{\text {trough }}\left(\theta_{m}-\theta_{\perp}\right) \frac{\exp \left(-\theta_{\perp}^{2} / 2 \sigma^{2}\right)}{\sigma \sqrt{2 \pi}}$,

with the total width $\sigma$ of Eq. 2-7. 
Figure 2-1 shows schematically what the angular scan looks like for a parabolic trough with cylindrical receiver, rim angle $\phi=90^{\circ}$, and concentration ratio $C=25$, for three values of the optical error: 0,5 , and 10 mrad. For this example, ( $\rho \tau \alpha)$ was assumed to be one; hence, the intercept factor equals the optical efficiency. From these curves, one sees that this test is most sensitive to data taken around the curved portion of the graph; data corresponding to the halfway point, on the other hand, do not provide any information on $\sigma_{\text {optical }}$.

Due to reflection and absorption losses, the radiation incident on the collector is attenuated by a factor $(\rho \tau \alpha)$, where

$$
\begin{aligned}
& \rho=\text { solar reflectance of reflector; } \\
& \tau=\text { solar transmittance of receiver glazing, if any; and } \\
& \alpha=\text { solar absorptance of absorber. }
\end{aligned}
$$

(The parentheses indicate that the factor is an effective transmittancereflectance-absorptance product, including secondary effects such as multiple reflections [9].) When the absorber surface is at ambient temperature, the heat loss is zero and the efficiency $n$ equals the optical efficiency:

$$
n\left(\theta_{m}\right)=n_{0}\left(\theta_{m}\right)=(\rho \tau \alpha) \gamma\left(\theta_{m}\right) \text {. }
$$

If the heat loss is not zero, an appropriate correction must be applied. Variation of $(\rho \tau \alpha)$ with $\theta_{m}$ is sufficiently small to be negligible for the present purpose.

Since $\gamma\left(\theta_{m}\right)$ depends on $\sigma_{\text {optical }}$ it is clear that an angular scan of $n\left(\theta_{m}\right)$ versus $\theta_{m}$ contains enough information to determine both ( $\left.\rho \tau \alpha\right)$ and $\sigma_{\text {optical }}$, at least in principle. 


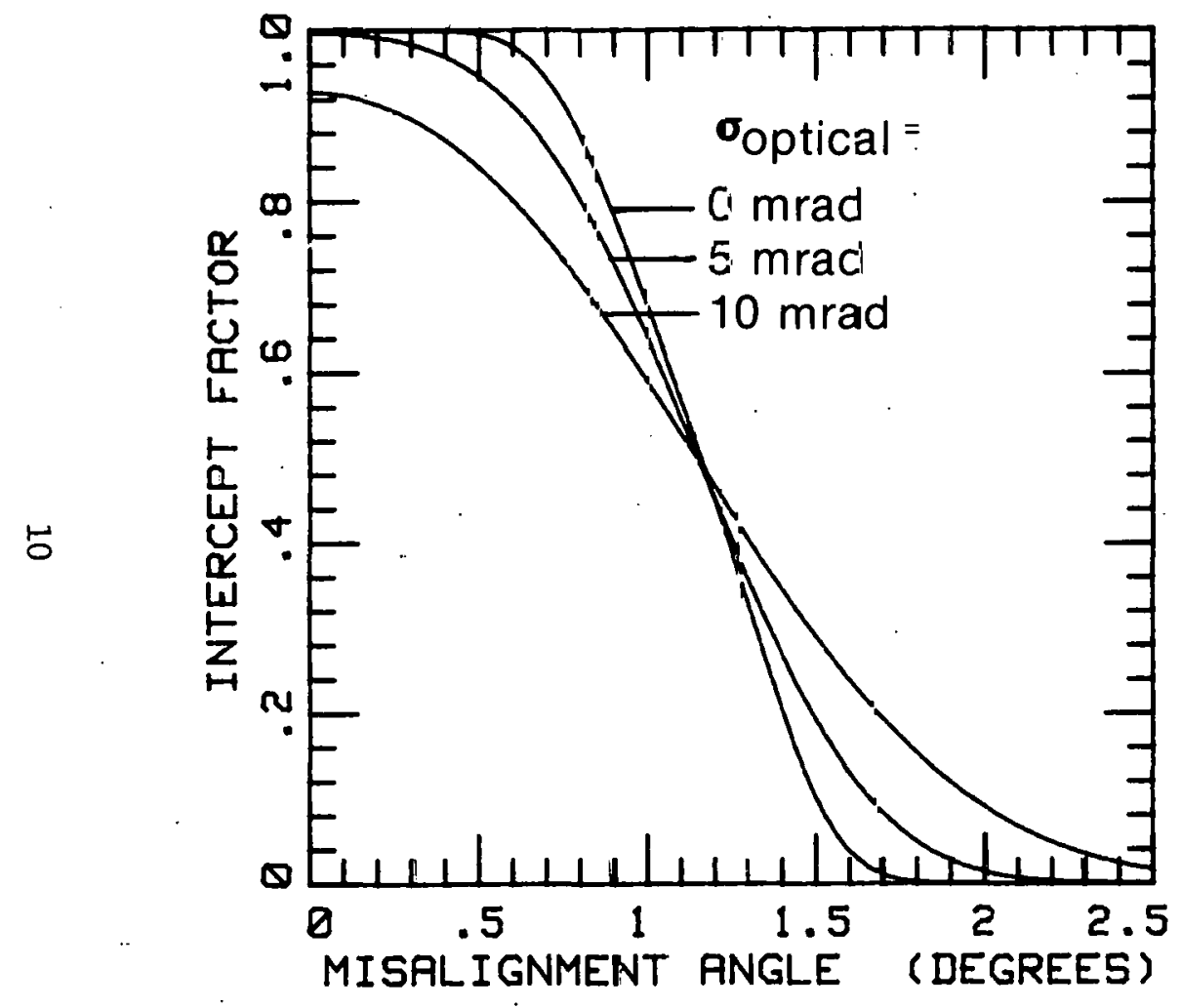

Figure 2-1. Intercept Factor vs. Misalignment Angle for $\sigma_{\text {optical }}=0,5$, and 10 mrad

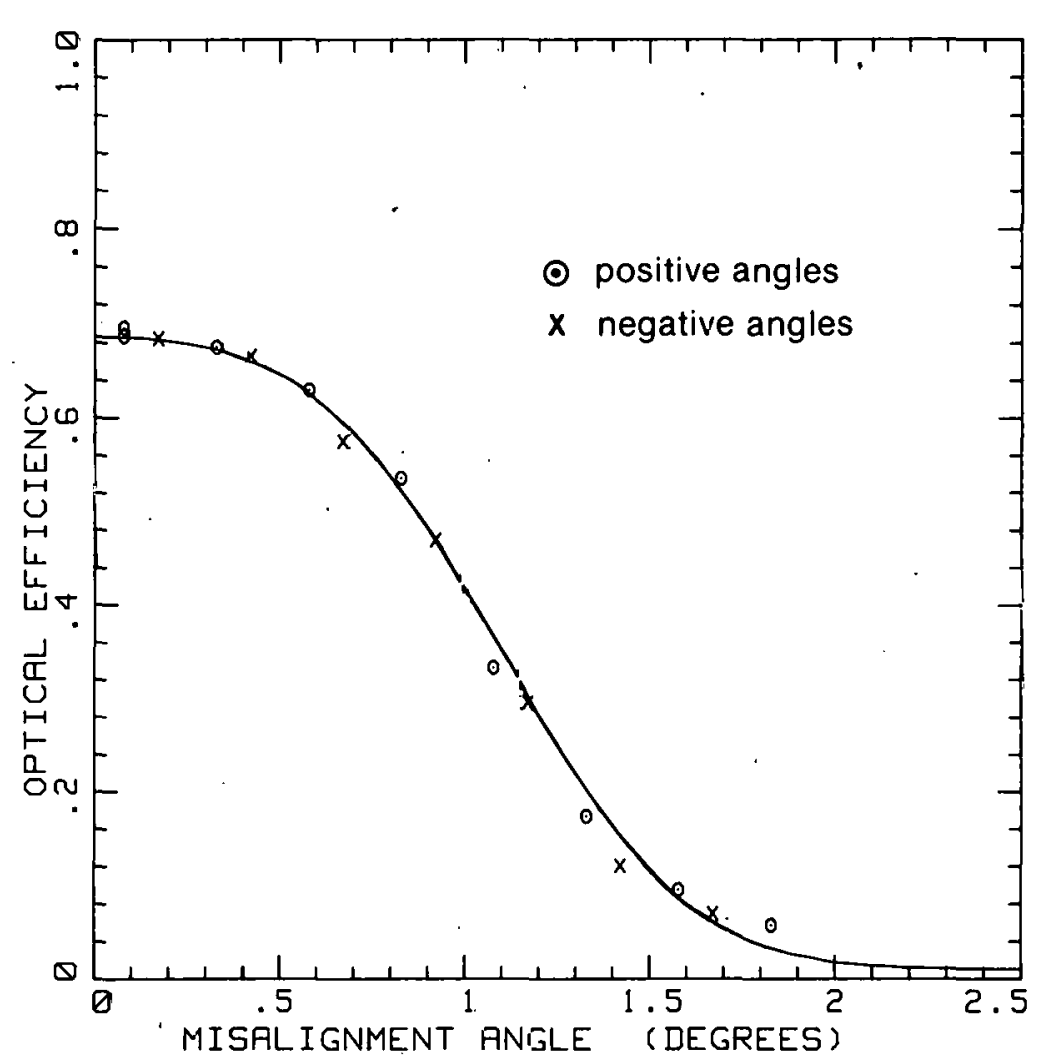

Figure 3-1. Test Data of Optical Efficiency vs. Misalignment Angle (Best Fit) 
SECTION 3.0

\section{EXPERIMENT}

In order to determine whether this method is accurate enough to be useful in practice, we decided to test a parabolic trough collector manufactured by Hexcel [10]. The test setup is described in another publication [11]. The collector has a cylindrical receiver coated with black chrome. The heat shield and receiver glazing originally supplied by Hexcel were removed for this test, so $(\rho \tau \alpha)$ is simply $\rho \alpha$. The reflector is made of an aluminum honeycomb substrate, coated with FEK-163, an aluminized second-surface acrylic film manufactured by the 3M Company. The rim angle of the collector is $\phi=72^{\circ}$, and the geometric concentration ratio is $C=20.9$. The tracking axis is horizontal in the east-west direction, and the tests were carried out at solar noon, so that the longitudinal incidence angle $\theta$ vanishes. The collector time constant was less than one minute, sufficiently short to perform an entire angular scan in half an hour. (If the time constant is much longer, a rotating test stand may be desirable.)

Inspection of the Hexcel collector after reassembly at SERI revealed that a significant amount of radiation missed the receiver. This suggested the possibility that receiver placement away from the design focal length of $0.915 \mathrm{~m}$ (36 in.) might improve the performance. We therefore set the recelver at several different distances from the reflector apex and each time visually realigned the two reflector halves (which are hinged at the apex) to maximize the intercept of radiation. We facilitated this visual reflector alignment by covering one reflector half while working on the other. By this procedure, we found that the thermal collector efficiency was maximized for a receiver placement slightly $(1.25 \mathrm{~cm})$ further away from the apex than the design focal length. All subsequent tests were carried out with the receiver in this new position.

A typical scan of $n_{0}\left(\theta_{m}\right)$ versus $\left(\theta_{m}\right)$ is shown in Fig. 3-1. Positive and negative values of $\theta_{m}$ have been included on the same side because of symmetry. Plotting $+\theta_{\mathrm{m}}$ and $-\theta_{\mathrm{m}}$ together has the advantage of pointing out any systematic eriur in the ecro alignment. A nonlinear least-squares fit to these data yields the values

and

$$
F^{\prime} \rho \alpha=0.690
$$

$$
\sigma=6.5 \mathrm{mrad}:
$$

In the test procedure, inlet and outlet temperatures of the fluid were measured and only the product $F^{\prime} n_{0}$ of heat extraction efficiency (also called collector efficiency factor [9]) and optical efficiency could be determined.

The theoretical scan corresponding to these parameters is shown by the solid line in Fig. 3-1. To evaluate the accuracy of this method, the scan was repeated several times, and $F^{\prime} \rho \alpha$ and $\sigma$ were calculated for each scan. The resulte are: 


\begin{tabular}{ccc} 
& $F^{\prime} \rho \alpha$ & $\sigma$ (mrad) \\
\hline & 0.691 & 6.4 \\
0.658 & 6.1 \\
0.685 & 6.8 \\
& 0.690 & 6.5 \\
& 0.708 & 6.1 \\
mean & 0.686 & $\underline{6.4}$ \\
\hline
\end{tabular}

The sample standard deviation for these five $\sigma$ measurements is 0.3 mrad, and indicates that the reproducibility of this method is about $5 \%$.

Lacking a reflectometer, we could not measure $\rho$ and $\alpha$ seperately. Published values for clean materials suggest $\rho \approx 0.85$ and $\alpha \approx 0.95$. F' is calculated to be close to unity and certainly larger than 0.95 (in fact, it did not change noticeably when spirals were inserted within the receiver to increase the turbulence). Hence, we would have expected $F^{\prime} \rho \alpha$ values greater than 0.77 . The low measured values may be because of materials degradation (for example, the reflector was visibly scratched), but the issue remains unresolved without further data.

In these tests, the misalignment angle was monitored quite accurately, hence the tracking error does not contribute significantly to the beam spread and

$$
\sigma_{\text {optical }}^{2}=4 \sigma_{\text {contour }}^{2}+\sigma_{\text {specular }}^{2}+\sigma_{\text {displacement }}^{2} .
$$

Assuming all rms width of 2.6 mrad for the sun, one therefore obtains from Eq. 2-3 the opelical error

$$
\begin{aligned}
\sigma_{\text {optical }} & =\left(6.5^{2}-2.6^{2}\right)^{1 / 2 \mathrm{mrad}} \\
& =6.0 \pm 0.3 \mathrm{mrad}
\end{aligned}
$$

for this experiment.

Unfuslunatcly, we did hul have a laser ray trace apparatus for an independent evaluation of the optical error. Measurements of $\sigma_{\text {specular }}$ and $\sigma_{\text {contour }}$ have been reported by Sandia Laboratories for reflectors also manufactured by Hexcel of a similar type but different focal length $[1,12$, and a communication with R. B. Pettit]. The contour error ranged from $1.8 \mathrm{mrad}$, beforc cnvironinental exposure, to $2.2 \mathrm{mrad}$, after three months in an envirunmental test

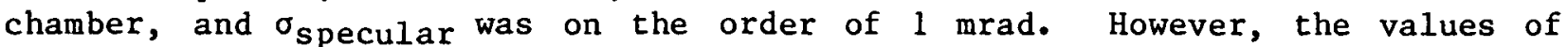
$\sigma_{\text {specular and }} \sigma_{\text {contour }}$ depend very much on how the FEK-163 film is bonded to the substrate. 
If these values of $\sigma_{\text {contour }}$ and $\sigma_{\text {specular }}$ were applicable to the Hexcel col-

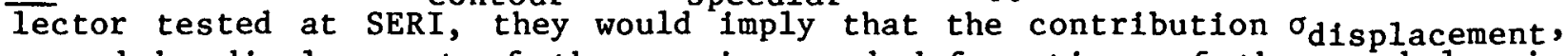
caused by displacement of the receiver and deformations of the parabola, is fairly large, on the order of $4 \mathrm{mrad}$. Visual inspection of the solar image at the receiver shows that the reflector is deformed; its curvature tends to be less than the design shape either because of the manufacturing process or because of weight-induced sag. A value of $4 \mathrm{mrad}$ for the associated beam spread may be realistic. In view of the difficulty of measuring $\sigma_{\text {displacement }}$ directly, and in view of the lack of laser ray trace data for the collector tested at SERI, one can invoke the Sandia data only for a qualitative comparison. To this extent, our results are certainly consistent with the Sandia data, but further work is needed to evaluate the accuracy of the method described in this paper. 


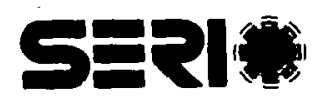


We have shown that the optical quality of focusing solar collectors can be determined by measuring the performance over a range of misalignment angles, and then comparing the data with calculated results. The calculated results de-

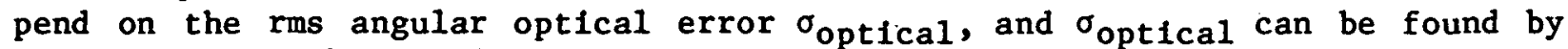
means of a nonlinear least-squares fit between data and calculation. The method has been tested on a parabolic trough collector and found to have acceptable reproducibility (better than 5\%). For point focus collectors, the angular scan can be carried out in several different azimuthal directions in order to provide information on, for example, gravity induced deformations. 


\section{REFERENCES}

1. Butler, B. L.; Pettit, R. B. "Optical Evaluation Techniques for Reflecting Solar Concentrators." Society of Photo-optical Instrumentation Engineers (SPIE). Optics Applied to Solar Energy Conversion: Vol. $114 ;$ p. 43 ; 1977.

2. Biggs, F.; Vittitoe, C. N. The Helios Model for the Optical Behavior of Reflecting Solar Concentrators. Albuquerque, NM: Sandia. Labs.; SAND 76-0354; March 1979.

3. American Society of Heating, Refrigerating and Air-Conditioning Engineers, Inc. ASHRAE Standard, Method of Testing to Determine the Thermal Performance of Solar Collectors: New York, NY: ASHRAE; 1978.

4. Bendt, P.; Rabl, A.; Gaul, H. W.; Reed, K. A. Optical Analysis and Optimization of Line Focus Solar Collectors. Golden, CO: Solar Energy Research Institute; SERI/TR-34-092. September 1979.

5. Bendt, P.; Rabl, A. Optical Analysis of Point Focus Parabolic Radiation Concentrators. Golden, $\mathrm{CO}$ : Solar Energy Research Institute; TR-333-336. In preparation.

6. Bendt, P.; Rab1, A. Effect of Circumsolar Radiation on Performance of. Focusing Collectors. Golden, CO: Solar Energy Research Institute; SERI/TR-34-093; 1980.

7. Pettit, R. B. "Characterization of the Reflected Beam Profile of Solar Mirror Materials." Solar Energy. Vol. 19: p. 733; 1977.

8. Cramer, H. Mathematical Methods of Statistics. Princeton, NJ: Princeton University Press; 1947.

9. Duffie, J. A.; Beckman, W. A. Solar Energy Thermal Processes. New York, New York: John Wiley and Sons; 1976.

10. Dudley, V. E.; Workhoven, R. M. Summary Report: Concentrating Sular Collector Test Results, Collector Module Test Facility. Albuquerque, NM: Sandia Labs; SAND 78-0815; May 1978.

11. Gaul, H. W.; Rab1, A. "Incidence Angle Modifier and Average Optical Efficiency of Parabolic Trough Collectors." ISES Conference. May 1979; Atlanta, GA. SERI/TP-34-246, to be published in ASME Journal of Solar Engineering. Vol. 1 (1980).

12. Allred, R. E. "Environmental Effects on Solar Reflector Structures." ISES Conference. May 1979; Atlanta, GA. To be published as a Sandia Labs report. 


\begin{tabular}{|c|c|c|c|}
\hline $\begin{array}{c}\text { Document Control } \\
\text { Page }\end{array}$ & $\begin{array}{c}\text { 1. SERI Report No. } \\
\text { TR-333-352 }\end{array}$ & 2. NTIS Accession No. & 3. Recipient's Accession No: \\
\hline \multirow{3}{*}{\multicolumn{3}{|c|}{$\begin{array}{l}\text { 4. Title and Subtitle } \\
\text { Determining the Optical Quality of Focusing Collectors } \\
\text { Without Laser Ray Tracing }\end{array}$}} & 5. Publication Date \\
\hline & & & \\
\hline & & & 6. \\
\hline \multicolumn{3}{|l|}{ 7. Author(s) } & 8. Periorming Organization Rept. No. \\
\hline \multicolumn{3}{|c|}{ P. Bendt, H. Gau1, A. Rab1 } & \\
\hline \multirow{4}{*}{\multicolumn{3}{|c|}{$\begin{array}{l}\text { 9. Performing Organization Name and Address } \\
\text { Solar Energy Research Institute } \\
1617 \text { Cole Boulevard } \\
\text { Golden, Co } 80401\end{array}$}} & 10. Project/Task/Work Unit No. \\
\hline & & & Task \#3432.10 \\
\hline & & & $\begin{array}{l}\text { 11. Contract (C) or Grant (G) No. } \\
\text { (C) }\end{array}$ \\
\hline & & & $(G)$ \\
\hline \multicolumn{3}{|c|}{ 12. Sponsoring Organization Name and Address } & $\begin{array}{l}\text { 13. Type of Report \& Period Covered } \\
\text { Technical Report } \\
\end{array}$ \\
\hline & & & \\
\hline
\end{tabular}

15. Suppiteríbilály Nules

16. Abstract (Limit: 200 words) This paper describes a novel alternative to the laser ray trace technique for evaluating the optical quality of focusing solar collectors. The new method does not require any equipment beyond what is used for measuring collector efficiency; it could therefore become part of routine collector testing. The total optical errors resulting from imperfect specularity and from inaccuracies in reflector position or, slope are characterized by an angular standard deviation $\sigma_{\text {optical }}$ the rms deviation of the reflected rays from the design direction. The method is based on the fact that the off-axis performance of a concentrator depends on $\sigma$ optical. An angular scan is performed; i.e., the collector output is measured as a function of misalignment angle over the entire range of angles for which there is measurable output (typically a few degrees). This test should be carried out on a very clear day, with receiver close to ambient temperature (if the latter condition cannot be satisfied, appropriate corrections are necessary). The parameter $\sigma_{\text {optical }}$ is then determined by a least-squares fit between the measured and the calculated angular scan. We tested the method on a parabolic trough collector manufactured by Hexcel, but it is suitable for parabolic dishes as well. The method appears to be accurate enough to determine $\sigma$ optith with about $10 \%$.

17. Document Analysis

a. Descriptors Concentrating Collectors ; Focusing Collectors : Measuring Methods ; Efficiency

b. Identifiers/Open-Ended Terms

c. UC Categories

62

18. Availability Statement

National Technical Information Service

U.S. Department of Commerce

5285 Port Royal Road

Springfield, Virginia 22161

19. No. of Pages

26

20. Price

$\$ 4.50$ 